arranged alphabetically, hence are randomized. Six items are in verse. Of 69 prose excerpts, 18 are fragments that convey little and hardly do justice to their authors. They could well have been replaced by longer passages from writers such as Bertrand Russell and Joseph Needham who are not represented.

Among the remainder are several which, I hope, will send readers back to the originals. Here is Haldane, in 1932, on the evolutionary process: "In the first place, it is very beautiful. In that beauty is an element of tragedy. ... . In an evolutionary line rising from simplicity to complexity, then often falling back to an apprarently primitive condition before its end, we perceive an artistic unity similar to that of a fugue". And here is Peter Medawar (1960), another polymath, writing less agreeably on the same subject: "It is a profound truth ... that nature does not know best; that genetical evolution, if we choose to look at it liverishly instead of with fatuous good humour, is a story of waste, makeshift, compromise and blunder".

Human evolution appears in questions asked by A.R. Wallace (1875) in an unfamiliar idiom: "whether we compare the savage with the higher developments of man, or with the brutes around him, we are alike driven to the conclusion that in his large and well developed brain he possesses an organ quite disproportionate to his actual requirements - an organ that seems prepared in advance, only to be fully utilized as he progresses in civilization".

Wallace also appears in an extract from Darwin's Autobiography of 1876 , where the author scolds himself for overlooking (in the 1840s) an important problem "the tendency in organic lines descended from the same stock to diverge in character as they become modified. The solution, as I believe, is that the modified offspring of all dominant and increasing forms tend to become adapted to many and highly diversified places in the economy of nature". An alternative autobiographical model is provided by Otto Frisch (1979), who describes a visit to his aunt, Lise Meitner, in exile in Sweden, which led to a major discovery in atomic physics. Or one may turn to H.G. Wells (1934) on his unsuccessful attempts, as a hamfisted student in the $1890 \mathrm{~s}$, to make apparatus, and his all too successful campaign to burlesque his professor; or to Miriam Rothschild writing cheerfully, in 1987 , on having seven years of work destroyed by a Nazi bomb.

The reader may also compare T.H. Huxley's famous account of a piece of chalk (1868) with Primo Levi's still more readable story of a carbon atom (1984). Rachel Carson's brilliant Silent Spring (1962) may be contrasted with E.J.H. Corner's lucid Life of Plants (1964). A problem outside the natural sciences is presented by S.J. Gould (1984) in a discussion of Adam's navel - an enigma indeed, for Adam was created, not born. These and other passages show that a few people with scientific training write well, even superbly. Classified and put briefly in context, they could have made a treasury to be read both for pleasure and for instruction. I especially emphasize the second purpose, for such a volume is needed to help in remedying a lamentable state of affairs - that most scientists still write badly.

S.A. Barnett is Emeritus Professor of Zoology in the Australian National University, Box 4 , GPO, Canberra, ACT 2601, Australia.

\section{Blaming biology?}

Daniel J. Kevles

Dangerous Dlagnostics: The Soclal Power of Blological Information. By Dorothy Nelkin and Laurence Tancredi. Basic Books: 1989. Pp. 207. \$18.95.

BIOMEDICAL research, especially in genetics and the neurosciences, has been generating an increasing range of new diagnostic methods and machines. Medical genetics can specify several thousand single-gene diseases and disorders, while magnetic resonance imaging, PET-scan and other techniques can detect numerous abnormalities in the brain. The new diagnostics reaches beyond the detection of physical maladies such as Tay-Sachs disease or brain tumours to identify tendencies to particular types of behaviour or mentality, drawing on recent scientific research that has found, for example, genetic sources for schizophrenia or brain lesions linked to learning disabilities. To be sure, the growth in diagnostic power has far outpaced therapeutic capacity. But never mind: diagnosis has its uses independent of cure. Diagnosis produces information about individuals that can assist life decisions they make for themselves - or that are made for them by others.

Genetic assessments have for some years figured in clinical settings, typically permitting prospective parents to learn the risk of conceiving a child that suffers from a genetic disease or assisting the physician in identifying the physical cause of a patient's malady. However, the broadening powers of neurophysiological and genetic tests are making them evermore appealing as devices to screen individuals with benefit, it is said enthusiastically, not only to themselves but to society. The National Institute of Mental Health has expressed a commonplace expectation: "Pre-symptomatic detection of psychiatric disease will be routine. Subjects at risk for alcoholism, schizophrenia, or depression may be identifiable well before the onset of clinical symptoms" (pp. 5-6). Families and physicians will thus be better prepared to take preventive action or apply therapeutic measures.

Diagnosis is similarly touted for use elsewhere in society. In the schools, it will assist teachers in dealing with troublesome children; in the courts, help specify the degree of a defendant's mental capacity; in the insurance world, aid in the determination of a client's health risk and, hence, premiums; and in the workplace, identify the propensity of workers to fall ill in response to, say, chemicals. According to the Journal of Occupational Medicine, diagnostic screening makes good business sense because it can "lead to reduced absenteeism, increased productivity, and decreased expenditures for workers' compensation and group health insurance" (p. 90).

In Dangerous Diagnostics, a critical survey and analysis of the diagnostic trend, Nelkin and Tancredi allow that the testing may indeed be valuable - as is, for example, DNA fingerprinting in the courts - but they argue, with arresting persuasiveness, that much of it is alarming. Nelkin, a sociologist at New York University, is an authority on the affairs of science and society. Tancredi directs the Health Law Program at the University of Texas Health Science Center in Houston. Their respective talents and expertise are advantageously joined in this book, which they wrote to stimulate debate about "the potential uses and abuses" of the emerging biological tests and as a kind of technology assessment addressed to their inherent social and political implications (p.ix).

Among the strengths of Nelkin and Tancredi's treatment is their insistence that the danger in diagnostics arises not so much in any evil intent as in the way that institutional contexts, and the values inherent in them, encourage the assessments to be used - and abused. A rapidly growing diagnostics industry presses the tests upon the world ("The future lies in genetic tendencies", an industrial biotechnologist has declared- p. 5). In the courts, reliance on 'hard' biological evidence of mental condition may improve the efficiency and reduce the costs of the judicial process; it can also exclude traditional psychiatric testimony that places the mental state of defendants, to their advantage, in a broader setting. Diagnostic screening in the workplace may improve productivity and decrease liability; it also shifts responsibility for workplace hazards from the company to the employee. Screening may better reveal an individual's risk of disease; but it enables health-care providers and 
insurance companies better to discriminate against potentially costly clients.

The dangers are amplified by an uncritical embrace of the science on which some of the diagnostics rest. Employers have been known to screen job applicants for characteristics - sickle-cell trait or pregnancy, for example - that are irrelevant to hazards in the employers' workplace. Depending upon the test, screening of a random population can yield a comparatively large number of false positives. Identification of a genetic risk for a disease such as manic depression is often taken to mean a genetic certainty to succumb; similarly with aberrant brain patterns. In both cases, the complex etiology of many diseases is ignored in favour of single-cause assessment and economic, social or medical stigmatization.

In the view of Nelkin and Tancredi, the diagnostic dangers revive an old theme a propensity to medicalize socioeconomic misfunction, to locate its principal causes in purely biological traits. In the ancient debate between nature and nurture, nature, they say, has recently been declared the winner. Blaming biology lets society or its constituent institutions off the hook; it permits them to segregate problems rather than deal with them. It fosters the construction of social categories - 'high-risk' employees or 'learning-disabled' children - and places them beyond the reach of meliorative social policy. Nelkin and Tancredi write, "By focusing attention on the physical state of the brain, educators may neglect the social and economic conditions leading to damage. By dealing with the biological characteristics of individuals, rather than the social causes of problems, schools set up solutions that insulate them from responsibility while enhancing their immediate control" (p.130).

Yet it should be remembered that diagnostics need not result in a deterministic medicalization. Identification of a biological handicap can make possible compensatory environmental remedy. It can also help society more knowledgeably define where it wishes to set the limits do haemophiliacs have an inalienable right to employment as butchers? - of regulatory or environmental accommodation. One wishes that Nelkin and Tancredi had given more attention to the technical quality of the new diagnostics, especially of the neurophysiological variety: technical reliability must inevitably figure in assessments of their appropriateness. One wishes, too, that they had explored more extensively the genuine challenges and trade-offs with which the new diagnostics confront society; for example, how the costs of risk should be allocated as risk becomes more sharply specified; or how institutional interests should be balanced against individual rights, particularly rights to education, employment, health care or privacy.

Not least because it points to the need for such explorations, Dangerous Diagnostics is an important and timely book, a thoughtful and informative provocation to debate. It is also a pathbreaking one, for its recognition that while the diagnostics may be applied across a broad informational and institutional spectrum, their increasing uses raise a class of social and political issues that are general, and generally disturbing. For as Nelkin and
Tancredi apprehensively declare, "If biological tests are used to conform people to rigid institutional norms, we risk reducing social tolerance for the variation in human experience. We risk increasing the number of people defined as unemployable, untrainable, or uninsurable. We risk creating a biologic underclass" (pp. 175-76).

Daniel J. Kevles is in the Division of the Humanities and Social Sciences, California Institute of Technology, Pasadena, California 91125, USA.

\section{The price of sex}

\section{Rory Howlett}

Sexual Selection. By James L. Gould and Carol Grant Gould. W.H. Freeman: 1989 Pp. 277. £16.95, \$32.95.

SEX is costly and in many ways disadvantageous, yet almost all species alive today reproduce sexually. Others, however, are either asexual or alternate between sexual and asexual phases, suggesting that there is a fine balance between the costs and benefits of sex

The subject is a controversial one, attended by a host of unanswered questions. In this addition to the Scientific American Library, James and Carol Gould set out to explain the roles that sex (technically, the recombination of separate sets of genes) and mate-acquisition

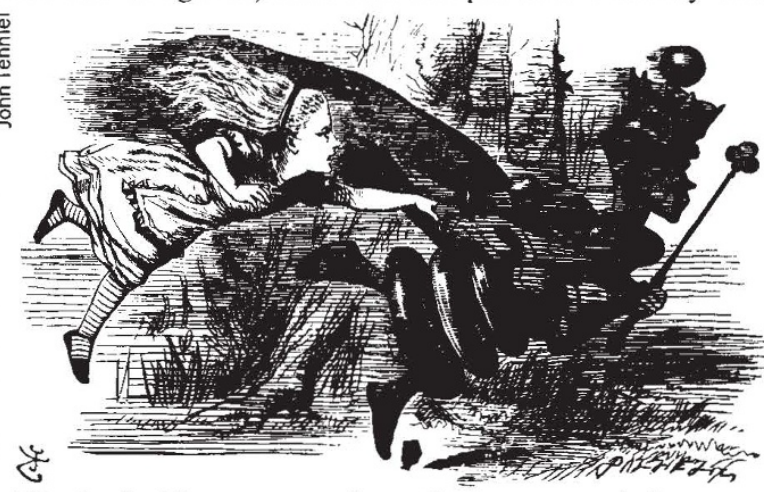

Like the Red Queen - running as fast as you can to keep up. strategies have had in the lives of organisms from bacteria to human beings, and to tackle some of those many questions.

The Goulds start by summarizing the origin and maintenance of sex, placing it squarely in the context of modern evolutionary thinking. Working on the assumption that there must be a powerful logic to explain the near ubiquity of sex, they compare and contrast an "embarrassment" of plausible hypotheses. Their conclusion is that, at the outset, the role of sex in genome repair was probably of overriding importance, while selection in response to ever-changing challenges (red-queen evolution) is likely to be the main factor maintaining sex in most modern species. The rest of the book con- centrates on the ways in which selection has affected the lives of sexually reproducing species, from non-social insects to the most social of all species, us. Here there are entertaining accounts of how animals choose and woo their mates, and how they use even the most devious of means to ensure that their genes are propagated in future generations; indeed, as has become almost obligatory since the publication of The Selfish Gene, a gene's eye view is taken throughout.

As the Goulds point out, the special challenge of behavioural ecology is to explain why there are so many different social organizations in the animal world, and why each species structures itself in the way it does. A particularly satisfying aspect of the book is the way that different social organizations are compared and related to the differences in habitat and niche; resource distribution and availability have a central role in determining the level of sociality that evolves.

Even within a species, individuals often vary in their behaviour, and it was previously believed that minority behaviours were somehow deviant. The authors do a fine job of explaining how frequency-dependent selection can give rise to a stable mixture of 'strategies' within species, an idea that has derived in large part from game theory. Equally well covered is the contentious topic of the evolution of female choice and its role in selecting for apparently disadvantageous (in terms of natural selection) male secondary sexual characters such as the tail of the peacock. Finally, we have a thoughtprovoking (and unashamedly 'sociobiological') account of the role of sexual selection in shaping human evolution and culture.

The Goulds write clearly yet with authority (both are involved in research on sexual selection) and lace the text with many fascinating facts and examples. Their book will do nicely for students and others with an interest in the subject.

Rory Howlett is an Assistant Editor of Nature 